\title{
Antifungal Potentialities of Chitosan and Trichoderma in Controlling Botrytis cinerea, Causing Strawberry Gray Mold Disease
}

Awad, H. M.

Agric. Botany Dept., Fac. of Agriculture, Menoufia Univ., Egypt

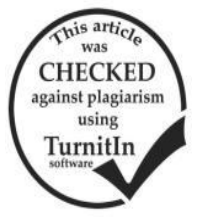

\section{ABSTRACT}

Strawberry gray mold disease caused by Botrytis cinerea (Pers.) is one of the most critical diseases attacking strawberry fruits especially at the post-harvest stage. This study compared the effectiveness of two types of Chitosan, bioagent's filtrates and fungicides in controlling the gray mold of strawberry. The commercial and synthesized in vitro Chitosan were tested on radial growth of B.cinerea on PDA agar plates and on infected four fruits cultivars strawberry. The results showed that the two types of Chitosan were significantly decreased infection of $B$. cinerea especially on un-wounded fruits that have been treated by dipping method. Biological control agents were used as culture filtrates for control strawberry gray mold pathogen both on wounded and unwounded fruits, the disease incidence was inhibited significantly in comparing to control treatment. Chemical fungicides were also used in these trials for controlling the gray mold disease. The results obtained confirm the superiority of fungicides in controlling the disease in comparing the commercial and synthesized Chitosan well as biocontrol agents.

Keywords: Strawberry gray mold disease, Botrytis cinerea, Chitosan, Biological control, Fungicides.

\section{INTRODUCTION}

Strawberry (Fragaria x ananassa Duch.) is one of the most important crops of exported vegetables in Egypt with 283471 ton in 2015 season with average 18.291 ton/feddan (Ministry of Agriculture, Economic sector, 2015). Egypt is considered the third largest producer of strawberry worldwide after the United States and Spain (Wu et al, 2012). Strawberry plants are attacked by several diseases which cause considerable losses in fruits yield. Strawberry fruits are perishable fruits during postharvest storage where they susceptible to dryness and mechanical injuries in addition to decay and physiological disorders. Gray mold disease caused by Botrytis cinerea is one of the most important diseases where it infected worldwide more than 200 plant species (Williamson et al, 2007). In strawberry cultivations, the stage of overwintering of Botrytis cinerea could be find as sclerotia or vegetative mycelium in all strawberry wintering parts (Braun and Sutton, 1987 and Sutton, 1998). B. cinerea could be attack strawberry plants during growth stages of flowering, fruiting and storage periods causing destructive effects (Sesan, 2003; Droby and Lichter, 2004). Also, B. cinerea is consider the main causal pathogen of strawberry postharvest decay (Maas, 1998). There are many different fungicides anti-Botrytis thus, the occurrence of fungicidal resistance in the fields is not surprising (Weber, 2011), for example, and Carbendazim were discarded from use against $B$. cinerea, the causal agent of gray mold disease, because the resistance for them (Leroux et al, 2002) as well as their high toxicity. On the other side, the use of synthetic chemicals to control fungal diseases is restricted due to their high toxicity, where the most gray mold fungicides are often applied at least 7 days pre harvesting which is considered unacceptable. On the other hand, natural ingredients and resistant inducers which can increasing plant defense could be used in controlling strawberry gray mold disease. In this respect, chitosan and some biocontrol agents are highly effective for this purpose. Chitosan is derived from glucan with chitin repeating units, Chitins is an abundance mucopolysaccharides are found in arthropods such as shrimps, craps and inferior plants such yeasts. It has been reported that chitosan has a fungicidal action against several fungi (Hirrano and Nagao 1989; Kendra et al, 1989). The inhibitory effect of chitosan was also demonstrated against many of soil born fungi (Stossel and Leuba; 1984; El Ghouth et al, 1990) and Rhizopus stolonifer (Yarahamdi et al, 2014). Also, chitosan was used to control post-harvest diseases of many fruits such as Pear (Yu et al, 2008) and Strawberry (Ge et al, 2010; Bhaskara et al, 2000). Chitosan is known to be a potential elicitor of many plant defense responses, including the accumulation of chitinases (Mauch et al, 1984) and synthesis of proteinase inhibitors in tomato leaves (Pearce and Ride, 1982). Chitosan has been approved by the U.S Environmental Protection Agency (EPA) and food additive approved by the U.S Food and Drug Administration (FDA).

This research aimed to throw a light on the antifungal potentialities of two types of chitosan (Commercial and synthetic) in controlling the gray mold disease on fruits of four strawberry cultivars in vitro and in vivo comparing with the antifungal potentialities of some Trichoderma spp. as bio-agents and some fungicides.

\section{MATERIALS AND METHODS}

\section{Source of Botrytis cinerea as a causal pathogen of strawberry gray mold disease: \\ Botrytis cinerea was isolated as a causal pathogen} of strawberry gray mold disease from diseased samples of naturally infected strawberry fruits showing gray mold symptoms which collected from three localities of strawberry fields i.e., Shebin El-kom, El-Bagour and ElShohada which belonging to Minufiya governorate. The infection percentage was estimated as diseased fruits in relation to the total healthy ones. The gray mold pathogen (Botrytis cinerea) isolates infecting strawberry fruits were isolated on Potato Dextrose Agar (PDA) medium. The resultant cultures were purified using the single spore culture or hyphal tip techniques according to Dhingra and Sinclair, (1985). The growing fungal colonies were transferred to slant tubes of PDA medium and then incubated for 7 days at $24^{\circ} \mathrm{C}$. The pure cultures of Botrytis cinerea isolates were examined microscopically and identified based on their morphological features at Agricultural Botany Department, Faculty of Agriculture, Minufiya University using the methods adopted by Neergard, (1945); Barnett, (1960) and Domsch et al., (1980) in addition to the key of imperfect fungi of Barnett and Hunter, (1972).

\section{Source of Trichoderma spp. isolates as antagonists:}

Trichoderma fungi were isolated from soil and rhizosphere samples of grown strawberry in the previously 
mentioned fields by uprooting the infected plants with great care to obtain most of the intact root system. The dilution plate method (DPM) was used for isolation of Trichoderma spp. The isolated Trichoderma fungi were cultured onto $20 \%$ malt extract agar, incubated for two days at $25^{\circ} \mathrm{C}$ then, identified according to Rifai, (1969) and Bissett, (1991). Stock cultures of isolated Trichoderma spp. were maintained on PDA slants then kept in a refrigerator at $5^{\circ} \mathrm{C}$ and they repeatedly sub-cultured every 4 weeks on fresh PDA slants.

Preparation of Trichoderma spp. culture filtrates:

Trichoderma culture filtrates were prepared by inoculating disk of the fungus onto liquid potato dextrose medium in flasks $(100 / 200 \mathrm{ml})$, then incubated by shaking at $25^{\circ} \mathrm{C}$ for 3 days then incubated for 7 days. Trichoderma culture filtrates were prepared by eliminating the mycelial mates, then the filtrates were centrifuged at $8000 \mathrm{~g}$ for 10 min., and filtered through a Hydrophobic filter (type A/E, Gelman Sciences, Ann Arbor, M1) (Harman et al, 1992).

\section{Source of chitosan:}

Two types of chitosan were used in this trail against $B$. cinerea where the first one is commercial chitosan (Ch.C.) which was purchased from Pharo-Pharma for Pharmaceuticals Address Plot 9, 3rd Industrial Zone, Block 16, Borg El Arab City, Alexandria, Egypt) while, the second one is synthesized Chitosan (Ch.S.) in vitro.

The production process of the synthesized chitosan in vitro involved three steps i.e., demineralization (DM), deproteinization (DP) and deacetylation (DA) as described by Youn et al., (2007). In this respect, the shrimp shells were demineralized with $1 \mathrm{~mol} / \mathrm{L} \mathrm{HCl}$ for $30 \mathrm{~min}$ at ambient temperature with a solid/solvent $(\mathrm{HCl})$ ratio of 1:15 (w/v). Following the DM step, the demineralized shells were collected on a 100-mesh sieve, washed to neutrality in running tap water, rinsed with deionized water, and filtered to remove excess moisture. The DP step was accomplished by treating the demineralized shells with $3 \mathrm{~g} / 100 \mathrm{~mL} \mathrm{NaOH}$ for $15 \mathrm{~min}$ at $15 \mathrm{psi}$ (atmospheric pressure) $/ 121^{\circ} \mathrm{C}$ and a solid/solvent $(\mathrm{NaOH})$ ratio of 1:10 (w/v). The residue was then washed, filtered as mentioned above, and dried at $60^{\circ} \mathrm{C}$ for 4-hrs in a forced-air oven. The DA step was achieved by treating chitin under conditions of $15 \mathrm{psi} / 121^{\circ} \mathrm{C}$ with 45 $\mathrm{g} / 100 \mathrm{~mL} \mathrm{NaOH}$ for $30 \mathrm{~min}$ and a solid/solvent ratio of 1:10 $(\mathrm{w} / \mathrm{v})$. The resulting chitosan was collected, washed as mentioned above and dried at $60^{\circ} \mathrm{C}$ for 4-hrs in a forced-air oven.

\section{Deacetylation degree (D.d):}

It was determined for the five chitosan samples by the potentiometric titration method described by Brous - signac, reported by Tolaimate et al., (2000).

Chitosan solution in a known excess of $\mathrm{HCl}$ was titrated with $0.1 \mathrm{M} \mathrm{NaOH}$ solutions, a curve with two inflexion points was obtained. The degree of deacetylation was determined through equation:

$$
\% \mathrm{NH2}=16.1(\mathrm{~V} 2-\mathrm{V0}) \times \mathrm{Mb} / \mathrm{W} \text {. }
$$

Where V0 and V2 are the base volumes (ml) referred to first and second inflexion points respectively, $\mathrm{Mb}$ is the base molarity in $\mathrm{g} / \mathrm{mol}, \mathrm{W}$ is the original weight of the polymer in $\mathrm{g}$.

The degree of deacetylation for prepared Chitosan was $85 \%$.

\section{Controlling $B$. cinerea using chitosan in vitro:}

In this trail, the two types of previously mentioned chitosan were used with $3 \mathrm{ml}$ of each one.
They were applied at different concentrations i.e., 0.5, $1.0,2.0$ and $2.5 \%$. The used chitosan solutions were dropped onto the surface of poured solid PDA medium in petri dish $(9 \mathrm{~cm})$, and then the drops were spread well till the complete absorption into media. The plates were inoculated with the inoculum disk $(4 \mathrm{~mm})$ of the tested fungal pathogen at the center of the dish.

Controlling $B$. cinerea using chitosan in vivo:

Both types of chitosan were applied by dipping and spraying at different concentrations i.e. 0.5, 1.0, 2.0 and $2.5 \%$ on wounded and un-wounded strawberry fruits. In case of dipping method, the fruits were soaked individually in the targeted concentration for five minutes, then raised and leaved for air drying. Then, the fruits (wounded and unwounded) were inoculated at the surface with an equal disk $(4 \mathrm{~mm})$ of the pathogen and left in foam plates then covered with stretch film till appearance of gray mold symptoms. The developed symptoms were daily investigated.

Controlling $B$. cinerea using Trichoderma spp. in vitro:

The antagonistic ability of tested three isolates of Trichoderma spp. was assessed against the pathogenic isolate $B$. cinerea that isolated from strawberry rotted fruits in dual culture according to the method described by Fokkema (1973). Three days old cultures of Trichoderma harzianum, T. hamatum and T. viride were used as sources of antagonistic inocula. An equal disc of each one of tested Trichoderma isolates $(4 \mathrm{~mm} \varnothing)$ was placed at $20 \mathrm{~mm}$ far from the edge of PDA plates $(9 \mathrm{~cm} \varnothing)$. A disc of pathogen was placed $50 \mathrm{~mm}$ away from the biocontrol fungal disc. Cultures were incubated in the dark at $25^{\circ} \mathrm{C}$ until the growth of the pathogen covered completely the check plates. The biological control agent inhibits the pathogen growth as a result of producing antagonistic metabolites, which decrease the rate of the pathogen growth.

The growth reduction percentage that pooled out was calculated using the following formula:

\% Growth reduction $=\frac{\text { Control }- \text { Tretment }}{\text { control }} \times 100$
Controlling strawberry gray mold infection using
Trichoderma spp. in vivo:
Three culture filtrates of tested Trichoderma isolates were assessed against the pathogenic isolate $B$. cinerea by two methods (dipping and spraying) on wounded and unwounded strawberry fruits. In dipping method, the fruits were soaked individually in each filtrate for five minutes, then raised and left for air drying. The treated fruits (wounded and unwounded) were inoculated on surface with disk of the pathogen inoculum and left in foam plates then covered with stretch film till appearance of gray mold symptoms. The developed symptoms were daily investigated.

Controlling strawberry gray mold using fungicides in vivo:

Three different fungicides i.e., Switch $62.5 \% \mathrm{WG}$ (Cyprodinil-Fludioxonil), Rovral 50\% WP (Iprodione) and Topsin-M70\% WP (Thiophanate-methyl) were used at three different concentrations i.e., 100, 150 and 200 ppm based on their active ingredients for controlling the gray infection on wounded and un-wounded strawberry fruits in case of spraying application only. Additionally, using 
results of the tested fungicidal treatments in in comparison with those of chitosan and Trichoderma treatments.

Disease assessment

Disease parameters were determined on rotted fruits according to the disease index rating which was made to determine the average diameter of the infected areas on fruit surface after seven days of inoculation. The following numerical rates were suggested to facilitate visual determination and to give a satisfactory comparison:

$0=$ No rot.

$1=$ Scattered small rot.

$2=$ Rots coalescing and including about $25-50 \%$ fruit area.

$3=$ More than $50 \%$ of the fruit area was infected.

Readings were converted to disease index according to the equation suggested by (Townsend and Heuberger, 1943) as follows:

Disease Severity \% $=\frac{\sum(n \times r 1)+(n \times r 2)+(n \times r 3)}{3 N \times 100}$

Where (n) is the number of fruits in each numerical rate; r1, r2 and $r$ are ratings and $(N)$ is the total number of inoculated fruits multiplied by the maximum numerical rate 3 .

Also the percentage of infected fruits was estimated.

Statistical analysis:

The collected data were subjected to statistical analysis using the F-test and means were compared by the LSD at 0.05 levels of probability as described by Snedecor and Cochran (1967) using Costat Software (1985).

\section{RESULTS AND DISCUSSION}

Pathogenicity test:

Data in Table (1) showed that the most virulent isolate of $B$. cinerea from Shebin El-kom district according to the pathogenicity test. This virulent isollate was used to achieve this study.

Table 1. Pathogenicity test for three Botrytis cineria isolates on different cvs. of strawberry fruits under controlled laboratory conditions.

\begin{tabular}{lccccc}
\hline Botrytis cineria & \multicolumn{5}{c}{ D.S \% on tested strawberry cvs. } \\
Isolates & Sana & Fortuna & Florida & Festival & Mean \\
\hline \multicolumn{5}{c}{ Wounded fruits } \\
Shebin El-kom & 85.3 & 84.9 & 84.5 & 84.5 & 84.8 \\
El-Bagour & 79.5 & 81.1 & 78.9 & 80.2 & 79.9 \\
El-Shohada & 78.4 & 79.4 & 81.2 & 79.9 & 79.7 \\
\hline \multicolumn{5}{c}{ Un-wounded fruits } \\
Shebin El-kom & 76.2 & 77.4 & 77.2 & 76.4 & 76.8 \\
El-Bagour & 74.1 & 73.8 & 74.3 & 73.6 & 73.9 \\
El-Shohada & 74.2 & 72.3 & 73.5 & 73.4 & 73.5 \\
\hline
\end{tabular}

\section{Controlling $B$. cinerea using chitosan in vitro:}

In plant disease management, natural products i.e. chitosan were increased in usage as disease control agent. Chitosan as a naturally polysaccharide, having inhibitory activity against many plant pathogenic fungi (Rabea et al., 2003; Xu et al., 2007). This direct antifungal activity of Chitosan in vitro in other findings confirmed with our studies (Allan and Hadwiger, 1979; Ait Barka et al., 2004).

Furusaki et al., 1996 reported that Chitosan is composed from three forms of reactive functional groups (an amino group, a primary hydroxyl group and secondary hydroxyl group) at the C-2, C-3, and C-6 positions of the glucosamine residue; respectively. A lot of useful materials had been provided in many fields of application as a result of the chemical modifications of these groups. (Kurita, 1986; Sugimoto et al., 1998). Chitosan is thought to have its antimicrobial effect due to the existence of (Ocarboxymethylated (O-CM)) and its exchange of the hydroxyl group in the C- 6 position of Chitosan with the acetyl group, which enhances the protonation of the amine group in the C-2 position in the presence of the new carboxyl ion (Liu et al., 2001).

Data in Table (2) indicate that all tested chitosan concentrations were effective in inhibiting fungal growth of $B$. cinerea in all experimental trials in petri dishes. In this respect, the commercial chitosan (Ch.C.) was more effective in inhibiting the growth of $B$. cinerea than the synthesized one (Ch.S.). The highly effective concentration of the two tested types of chitosan in vitro was $2.5 \%$ while, the least effective concentration was $0.5 \%$ of both tested chitosan types. On the other hand, all tested concentrations of the two chitosan types were effective in inhibiting the growth of $B$. cinerea compared with control treatment. There was a clear gradually increase in in inhibiting the growth of $B$. cinerea in vitro for both types of chitosan with increasing the tested concentrations.

Table 2. Effect of two types of chitosan in vitro on growth of $B$. cinerea the causal organism of strawberry gray mold disease.

\begin{tabular}{lcccccc}
\hline \multirow{2}{*}{ Chitosan } & Concentration & \multicolumn{4}{c}{ Linear Growth $(\mathbf{m m})$} & \multirow{2}{*}{ Mean } \\
\cline { 3 - 6 } & $\mathbf{\%}$ & $\mathbf{T 1}$ & $\mathbf{T 2}$ & $\mathbf{T 3}$ & $\mathbf{T 4}$ & \\
\hline & 0.5 & 55.2 & 54.3 & 54.6 & 56.1 & 55.05 \\
Ch.S. & 1 & 44.2 & 45.7 & 44.8 & 45.6 & 45.08 \\
& 2 & 29.7 & 28.8 & 28.7 & 28.8 & 29.00 \\
& 2.5 & 17.2 & 15.9 & 15.4 & 16.2 & 16.18 \\
\hline & 0.5 & 50.7 & 50.2 & 49.4 & 49.7 & 50.00 \\
Ch.C. & 1 & 41.2 & 40.8 & 42.1 & 40.6 & 41.18 \\
& 2 & 20.4 & 23.1 & 20.5 & 22.4 & 21.60 \\
Control & 2.5 & 12.5 & 11.4 & 11.9 & 13.2 & 12.25 \\
& & 90 & 90 & 90 & 90 & 90.00 \\
\hline
\end{tabular}

LSD at $0.05 \% \quad$ Ch $=0.46335 \quad$ Con. $=0.73262 \quad$ Ch $\times$ Con.$=1.0360$ ${ }_{*} \mathbf{T}=\mathbf{T r i a l} \mathbf{C h}=$ Chitosan $\quad$ Con.= Concentration

In this study the treatment with two types of Chitosan showed positive effect against $B$.cinerea radial growth in petri dishes. Also we showed that the growth reduction level is correlated with the concentration of Chitosan .Du et al., ( $199 \vee$ ) mentioned that Chitosan inhibited the growth of the $B$.cinerea significantly on artificial media .Siti et al., ( $\uparrow \ldots 9)$ reported that after 3-day culture the pathogen colony diameter in P.D.A medium containing $0 \%, 0.05 \%$ and $0.20 \%$ Chitosan were $77.4 \mathrm{~mm} 70 . \Sigma \mathrm{mm}$ and $25.6 \mathrm{~mm}$ respectively.El Ghaouth et al., ( ( 994 ) explained that $0.6 \%$ Chitosan inhibited radial growth of $B$.cinerea and Rhizopus stolonifer by $95.5 \%$ and $71.5 \%$.

\section{Controlling strawberry gray mold infection using} chitosan in vivo:

Data in Table (3) show that both types of chitosan (Ch.C. and Ch.S.) with different concentrations which applied as dipping treatment decreased disease severity $\%$ on wounded and unwounded strawberry fruits which inoculated with $B$. cinerea when compared with control treatment (fruits treated with pathogenic fungi only). In this respect, increasing the concentration of chitosan decreased gradually the determined disease severity $\%$. However, the tested concentrations of Ch.C. were generally more effective than those of Ch.S. in controlling strawberry gray mold infection. Also, no one of the four-tested strawberry cultivars exhibited clear resistant to gray mold infection more than others with the two types of chitosan at all tested 
concentrations on wounded and un-wounded fruits. There were no significant differences between the four strawberry cultivars in disease index on the same level of each concentration of Chitosan types.

Table 3. Effect of chitosan as dipping application on gray mold infection caused by $B$. cinerea on wounded and un-wounded strawberry fruits of different cvs.

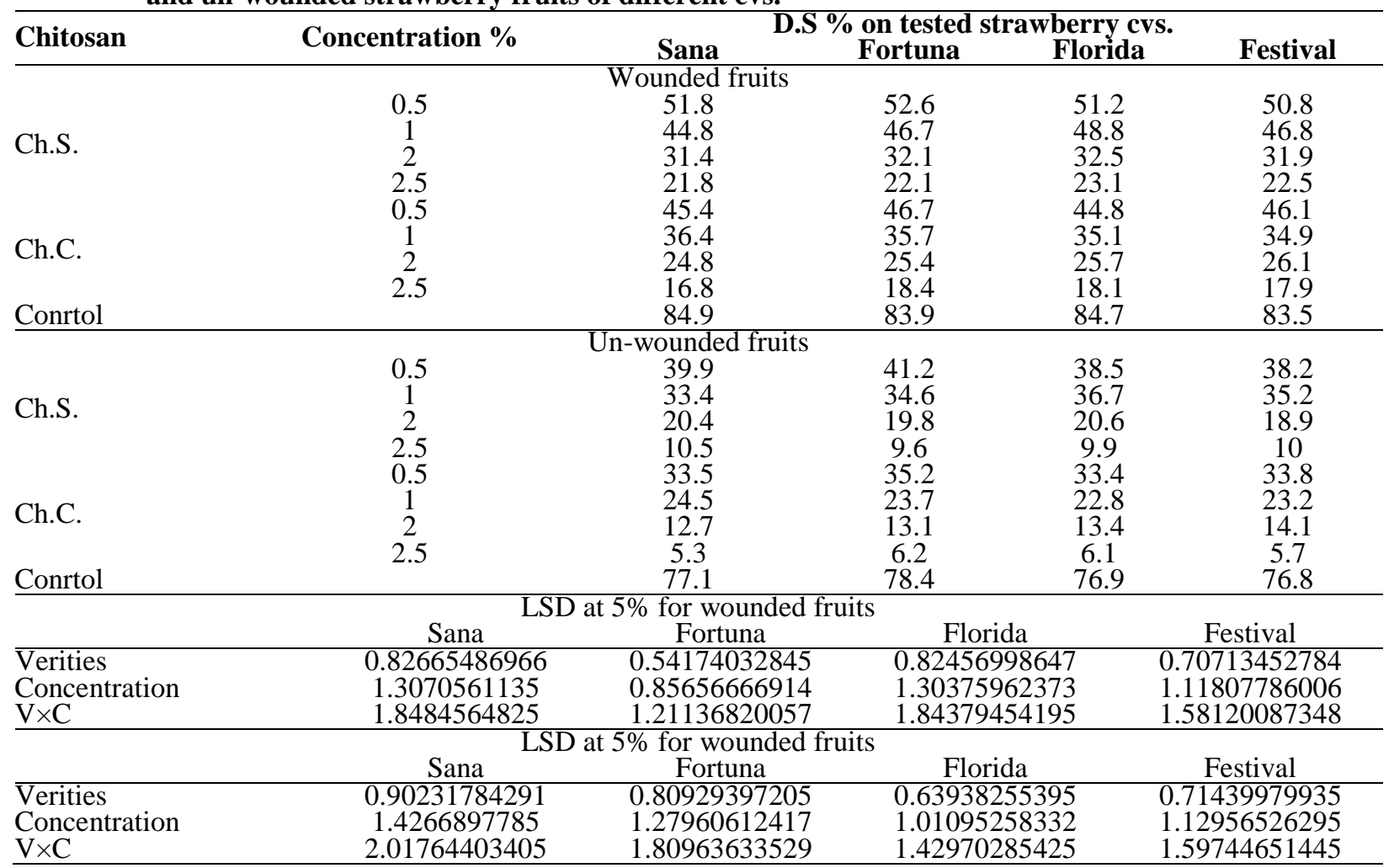

As for the sprayed strawberry fruits with the two types of chitosan, data in Table (4) indicate that the sprayed strawberry fruits with Ch.C type of chitosan were more effective in reducing the strawberry gray mold infection at all tested concentrations than those sprayed with Ch.S type of chitosan. The highest effective concentration in reducing the gray mold infection was $2.5 \%$ while, the least effective one was $0.5 \%$ with either of Ch.C or Ch.S types of chitosan on wounded and un-wounded strawberry fruits. The effect of $2.5 \%$ concentration of Ch.C or Ch.S types of chitosan was better on un-wounded fruits than wounded ones where the least DS\% was recorded on fruits of cv. Sana followed by fruits of cvs. Festival, Florida and Fertona. In general, application with chitosan on strawberry fruits either by spraying or dipping was effective in decreasing DS\% when compared with control of wounded or un-wounded fruits.

According to the bio-compatible and nontoxic properties of Chitosan (Wu et al., 2005), because of this chitosan occupy the place of fungicides in agriculture fields (Bautista-Baños et al., 2006). Chitosan activity against $B$. cinerea have been demonstrated in other findings (Ait Barka et al., 2004; Trotel-Aziz et al., 2006 and Aziz et al., 2006) the antifungal effect of chitosan had been verified on grape plantlets downy mildew (Aziz et al., 2006), Romanazzi et al., 2002, 2006 and 2007 have proven the effective of chitosan against botrytis bunch rot on grapes when applied as a postharvest spray or dipping. In our study both types of Chitosan; whether in dipping or spraying application on un-wounded fruits, showed a great activity against gray mold disease caused by $B$. cineria.
Chitosan has greatly contributed to reducing the progression of the disease and its spread to fruits throughout the storage period, also kept the fruits in a fresh and vibrant form. This leads us to the other characteristics of Chitosan as a strong elicitor instead of an antimicrobial agent, In addition to the effect in plant disease control.

The induced plant defense response is greatly correlated with the enzymatic response; many findings demonstrate that Chitosan is external elicitors that improving host defense such as in tomato, Chitosan induced the production of phenolic and phytoalexine compounds; this explain is precedes the role of hydrolytic enzymes of Fusarium oxysporium f. sp. radicislycopersici (Benhamou and theriault, 1992). Other report showed the induced resistance of Chitosan against Fusarium oxysporium in susceptible tomato plants when applied as a seed, root coating or plant spraying, these treatments inhibit Fusarium growth to the external root tissues and can improve some defense reaction including structural barriers (Benhamou et al., 1998). On the contrary of our results Ben-shalom et al., 2003 reported that, the anti-fungal activity of chitosan was not enough in cucumber plants to inhibit the pathogen of gray mold disease.

In our study, on PDA medium the highly concentrations of Chitosan $(2.5 \%)$ (Table 1) was the only concentration that inhibits fungal growth, while it was strongly inhibitory on fruits at the same concentrations (Table 2); because this reason various reactions were activated in strawberry fruits, this effect is likely to be referenced to the Chitosan-induced resistance to fungi 
strongly results from the stimulation of the plant's natural defense metabolism.

Certainly there were differences between the synthesized in vitro Chitosan (Ch.S.) and the commercial Chitosan (Ch.C.) formulation, this could be arises because the preparation techniques. Indeed, dissolving the Chitosan in the acids, it is necessary to prepare the solutions more than one day in advance and to monitor and adjust the $\mathrm{pH}$; in contrast, the commercial one can be prepared before the application by $1-2 \mathrm{~h}$, by dissolving the powder in water directly. Moreover, the final commercial Chitosan solution with formulation has a lower viscosity than the Chitosan acetate, for this reason the application with commercial chitosan more easily.

Table 4. Effect of chitosan as spraying application on gray mold infection caused by $B$. cinerea on wounded and un-wounded strawberry fruits of different cvs.

\begin{tabular}{|c|c|c|c|c|c|}
\hline \multirow[t]{2}{*}{ Chitosan } & \multirow{2}{*}{ Concentration \% } & \multicolumn{4}{|c|}{ D.S \% on tested strawberry cvs. } \\
\hline & & Sana & Fortuna & Florida & Festival \\
\hline \multirow{6}{*}{ Ch.S. } & & Wounded fruits & & & \\
\hline & 0.5 & 63.6 & 64.9 & 62.2 & 61.9 \\
\hline & 1 & 57.1 & 58.3 & 60.4 & 58.9 \\
\hline & 2 & 44.1 & 43.5 & 44.3 & 42.6 \\
\hline & 2.5 & 34.2 & 33.3 & 33.6 & 33.7 \\
\hline & 0.5 & 57.2 & 58.9 & 57.1 & 57.5 \\
\hline \multirow{3}{*}{ Ch.C. } & 1 & 48.2 & 47.4 & 46.5 & 46.9 \\
\hline & 2 & 36.4 & 36.8 & 37.1 & 37.8 \\
\hline & 2.5 & 29 & 29.9 & 29.8 & 29.4 \\
\hline \multirow[t]{2}{*}{ Control } & & 84.9 & 83.9 & 84.7 & 83.5 \\
\hline & & Un-wounded fruits & & & \\
\hline \multirow{5}{*}{ Ch.S. } & 0.5 & 45.6 & 47.1 & 44.4 & 45.1 \\
\hline & 1 & 39.3 & 42.6 & 40.0 & 40.4 \\
\hline & 2 & 26.1 & 26.5 & 25.4 & 24.8 \\
\hline & 2.5 & 15.5 & 16.4 & 15.8 & 15.9 \\
\hline & 0.5 & 39.4 & 41.1 & 39.3 & 39.7 \\
\hline \multirow{3}{*}{ Ch.C. } & 1 & 30.4 & 29.6 & 28.7 & 29.1 \\
\hline & 2 & 18.6 & 19.9 & 19.3 & 20.0 \\
\hline & 2.5 & 11.2 & 12.1 & 12.0 & 11.6 \\
\hline \multirow[t]{3}{*}{ Control } & & 77.1 & 78.4 & 76.9 & 76.8 \\
\hline & & $5 \%$ for wounded 1 & fruits & & \\
\hline & Sana & Fortuna & & & Festival \\
\hline Verities & 0.77715613942 & 0.75709624431 & 0.7 & 3538 & 0.60051102987 \\
\hline Concentration & 1.22879174907 & 1.19707426998 & 1.2 & 2271 & 0.94949130722 \\
\hline \multirow[t]{3}{*}{$\mathrm{V} \times \mathrm{C}$} & 1.73777395687 & 1.69291866778 & 1.7 & 5224 & 1.34278348402 \\
\hline & LS & at $5 \%$ for wounded 1 & fruits & & \\
\hline & Sana & Fortuna & & & Festival \\
\hline Verities & 0.91885816938 & 0.52561347844 & 0.6 & 5357 & 0.73400859235 \\
\hline Concentration & 1.45284233095 & 0.83106788038 & 1.0 & 3351 & 1.16056948698 \\
\hline $\mathrm{V} \times \mathrm{C}$ & 2.05462932842 & 1.17530746769 & 1.4 & 2411 & 1.64129310856 \\
\hline
\end{tabular}

3. Controlling B. cinerea using Trichoderma spp. in vitro:

Data in Table (5) indicate that $T$. harzianum isolate was the most effective one in reducing the growth of $B$. cinerea comparing with $T$. hamatum and $T$. viride. On the other and, the highest growth reduction\% was recorded with $T$. harzianum with clear inhibition zone with appearance of over growthing on growth of $B$. cinerea followed by $T$. hamatum which exhibited wide inhibition zone comparing with $T$. viride. $T$. harzianum isolate was the only one exhibiting over growthing on growth of $B$. cinerea without appearance of inhibition zone.

Table 5. Effect of Trichoderma spp. on growth of $B$. cinerea the causal organism of strawberry gray mold in vitro.

\begin{tabular}{|c|c|c|c|c|}
\hline \multirow{2}{*}{ Bioagents } & \multicolumn{2}{|c|}{ Botrytis cinerea } & \multicolumn{2}{|c|}{ Bio-interaction } \\
\hline & Linear growth (mm) & Growth reduction \% & Over growth (mm) & Inhibition zone (mm) \\
\hline T. hamatum & 20 & 73.77 & - & 4 \\
\hline T. harzianum & 18 & 80.00 & 12 & - \\
\hline T. viride & 23 & 74.44 & - & 1 \\
\hline LSD at $0.05 \%$ & $\lg =3.44500556847$ & $\mathrm{gr}=3.42080553082$ & $\mathrm{og}=1.40641763397$ & $\mathrm{iz}=1.08940641483$ \\
\hline
\end{tabular}

Zimand et al., 1996 showed that the isolate $T$. harzianum $\mathrm{T} 39$ reduced the B.cinerea biomass by 20 to $50 \%$, this reduction was due mainly to the effect on germtubes elongation and the germination rate was partially affected. The effect of the rate of T. harzianum T-39 on control efficacy varies with the host and disease system. In earlier studies the lower rate was superior for control B.cinerea the causal of tomato grey mould, similar to the findings in this study, but was inferior in controlling cucumber white and grey mould in commercial greenhouses (Elad, 2000).

\section{Controlling strawberry gray mold infection using Trichoderma spp. in vivo:}

Data in Table (6) show that dipping or spraying the wounded and un-wounded strawberry fruits in or with three sterilized culture filtrates of three Trichoderma isolates pre-inoculation with $B$. cinerea in vivo affected greatly the gray mold infection on the four-tested strawberry cvs. where the recorded DS\% were lesser than those recorded with control treatment. In this respect, dipping treatment was more effective in reducing gray mold infection than spraying treatment with the four-tested strawberry cvs. with superiority of them on un-wounded 
fruits than wounded ones. On the other hand, T. harzianum treatment was the most effective one followed by $T$. hamatum and $T$. viride respectively whether in case of dipping or spraying treatments with the four-tested strawberry cvs. Furthermore, the least DS\% was recorded on treated strawberry fruits cv. Florida by dipping on unwounded and wounded fruits respectively. Whereas, the highest DS\% was recorded in case of sprayed fruits of cv. Fertona with culture filtrates of $T$. viride.

In addition, the culture filtrate of the antagonistic fungus, T. harzianum was found to be more efficiency than

Table 6. Effect of Trichoderma culture filtrates as dipping or spraying applications on strawberry gray mold infection caused by $B$. cinerea on wounded and unwounded fruits.

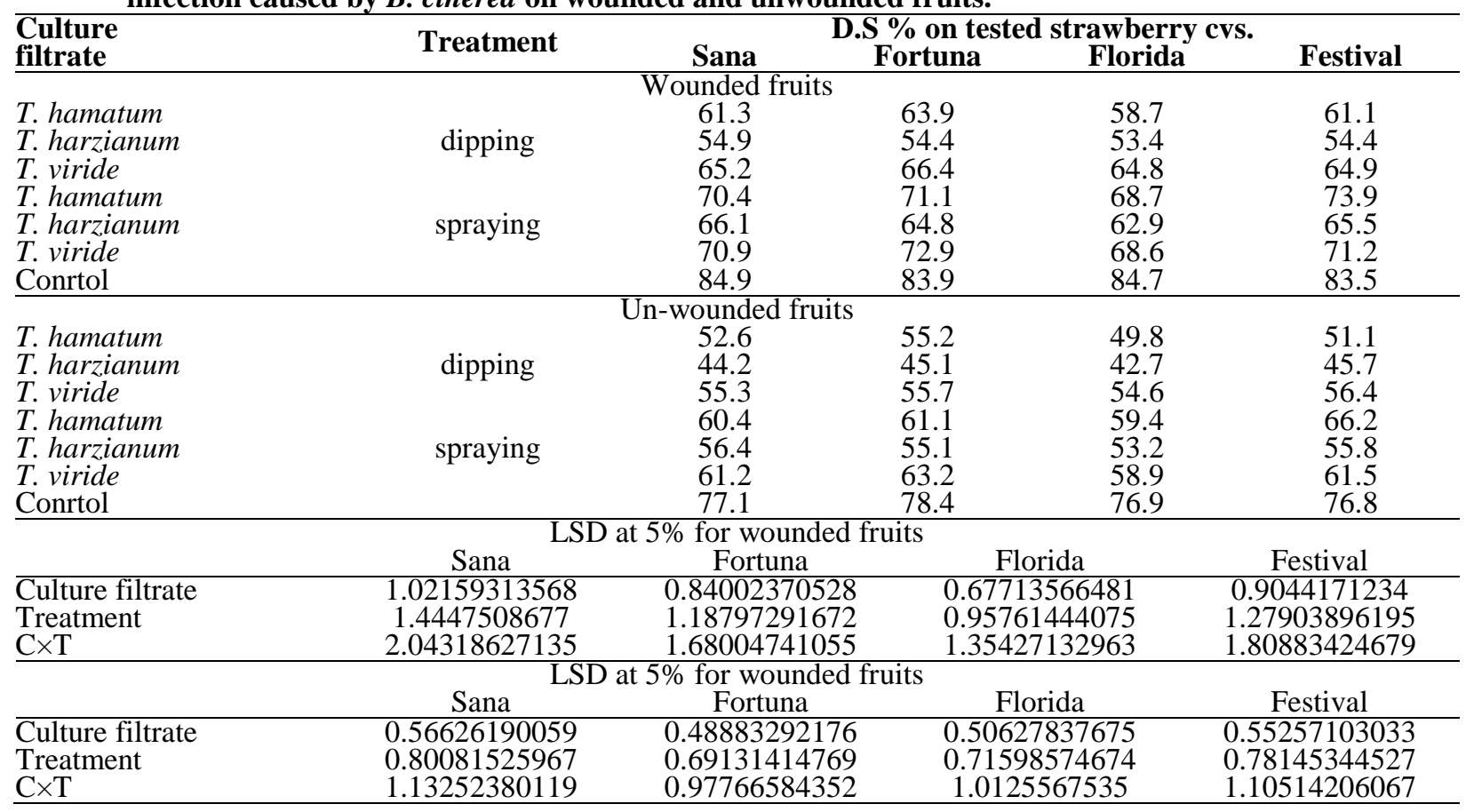

- Controlling strawberry gray mold infection using fungicides in vivo:

Data in Table (7) show that the three tested fungicides with different concentrations as spraying treatment decreased clearly the determined DS\% on wounded and unwounded strawberry fruits infected with $B$. cinerea comparing to control (inoculated fruits with $B$. cinerea only). Also, results indicate that increasing the concentration of each one of the tested fungicides decreased gray mold infection on treated fruits. The best concentration for use was $200 \mu \mathrm{g} / \mathrm{L}$ where the recorded DS\% of Switch and Topsin-M fungicides was $0.0 \%$ on all wounded fruits of the four-tested strawberry cvs. As for un-wounded fruits, Switch at 150 and $200 \mu \mathrm{g} / \mathrm{L}$ was the best one where the recorded DS\% was $0.0 \%$ on all treated fruits of the four-tested strawberry cvs. Meanwhile, Topsin-M and Rovral fungicides at 200 $\mu \mathrm{g} / \mathrm{L}$ only came in the second rank where the recorded DS\% was $0.0 \%$ on all un-wounded treated fruits of the four-tested strawberry cvs.

Generally, spraying strawberry fruits with fungicides pre-inoculation with $B$. cinerea was more effective in controlling the gray mold infection on unwounded fruits than wounded ones. There were slight differences between the four strawberry cultivars in the determined DS\% at the same level of each concentration the other culture filtrates in decreasing the growth of B.cinerea, but with less level than Chitosan. Similar results were observed where T.harzianum decreased the growth of Fusarium oxysporium, Verticillium albo-atrum and Fusarium culmorum (Ibrahim, 1997 and Hemeida, 1992). Abdulrahman (2005) reported that the bioagent culture filtrate of T.harzianum effected on radial growth of B.cinerea, Fusarium oxysporium and Rhizoctonia solani, but this effect was less than the action of some plant extracts. (using of fungicides in these study to find alternative control treatment instead of toxicity effects of chemicals).

Table 7. Effect of three fungicides as spraying treatment on strawberry gray mold infection caused by $B$. cinerea on wounded and unwounded fruits of four cvs.

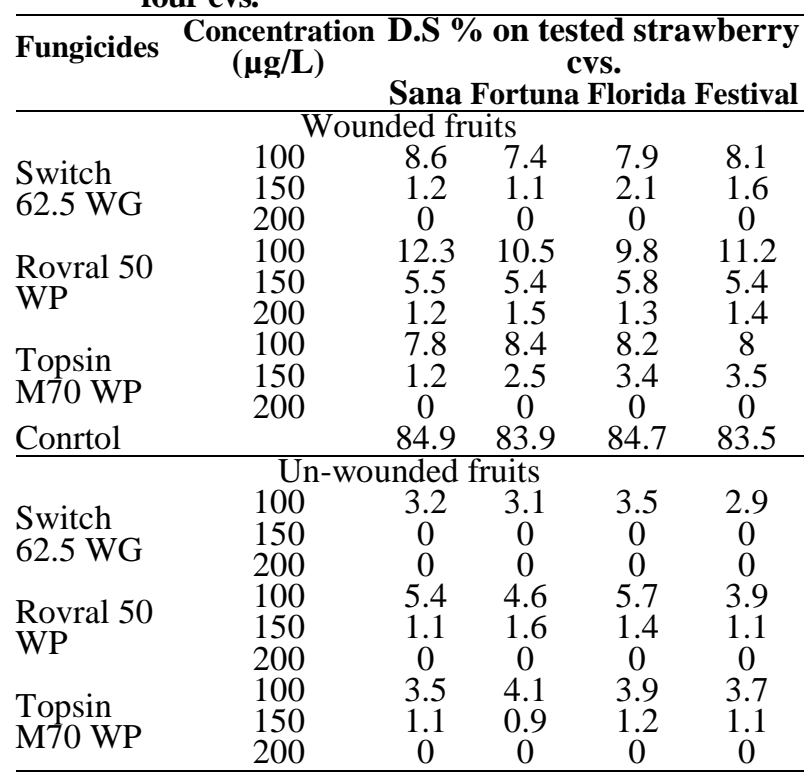


In this study, we tried to shed light on the alternatives to fungicides, as long as they give very close results in resistance to many plant diseases. The efforts to find naturally- occurring products having antimicrobial and activities in controlling pathogens actions in hosts like chitosan and its derivative has been getting more attention in these studies. We can outline, that the chitosan can be used on plant hosts to reduce or control disease levels and stopping the development of the pathogen action and minimizing the yield losses in quality and quantity. However, chitosan needs to understand the mechanism and action of disease resistance inducer.

\section{REFERENCES}

Abdulrahman, A.A., 2005. Antifungal activity of some extracts against some plant pathogenic fungi. Pakistan journal of Biological Sciences. 8 (3): 413 417.

Ait Barka, E.; Eullaffroy, P.; Clément, C.; Vernet, G. 2004. Chitosan improves development, and protects Vitis vinifera L. against Botrytis cinerea. Plant Cell Rep, 22, 608-614

Allan, C. R., and Hadwiger, L. A. 1979. The fungicidal effect of chitosan on fungi of varying cell wall composition. Exp. Mycol. 3:285-287.

Aziz A, Trotel-Aziz P, Dhuicq L, Jeandet P, Couderchet M, Vernet G, 2006. Chitosan oligomers and copper sulfate induce grapevine defense reactions and resistance to gray mold and downy mildew. Phytopathology 96, 1188-94.

Barnett, H.L. 1960. Illustrated Genera of Imperfect Fungi Burgess Publishing Company, Minneapolis 15, MN, USA, p. 225.

Barnett, H.L. and Hunter, B.B. 1972. Illustrated genera of imperfect fungi. Minnesota Burges Publ. Co. $241 \mathrm{P}$.

Bautista-Banos, S., Hernandez-Lauzardo, A.N., Velazquez-del Valle M.G., Hernandez-Lopez, M., Ait Barka, E., Bosquez-Molina, E., Wilson C.L. 2006. Chitosan as a potential natural compound to control pre and postharvest disease of horticultural commodities. Crop Protection. 25 ; $108-118$.

Benhamou, N., Kloepper, J.W., Tuzun, S., 1998. Induction of resistance against Fusarium wilt of tomato by combination of chitosan with an endophytic bacterial strain: ultrastructure and cytochemistry of the host response. Planta 204, 153-168.

Benhamou, N., Theriault, G., 1992. Treatment with chitosan enhances resistance of tomato plants to the crown and root pathogen Fusarium oxysporum f. sp. radicis-lycopersici. Physiol. Mol. Plant Pathol. 41, 34-52.

Ben-Shalom N, Ardi R, Pinto R, Aki C, Fallik E, 2003. Controlling gray mould caused by Botrytis cinerea in cucumber plants by means of chitosan. Crop Protection 22, 285-90.

Bhaskara RMV, Belkacemi K, Corcuff R, Castaigne F, Arul J. 2000. Effect of pre-harvest chitosan sprays on post-harvest infection by Botrytis cinerea and quality of strawberry fruit. Postharvest Biol. Technol. 20:39-51.

Bissett, J. (1991). A revision off the genus Trichoderma. II. Inferagenetic classification. Con. J. Bot., 69: $2357-$ 2372.

Braun, P. G. and J. C. Sutton. 1987. Inoculum sources of Botrytis cinerea in fruit rot of strawberries in Ontario. Can. J. Plant Pathol. 9: 1-5.
Costat Software (1985). User's Manual Version 3 CoHort. Tusson, Arisona, U.S.A.

Dhingra, O.D. and Sinclair, J.B. 1985. Basic Plant Pathology Methods. CRC Press, Boca Raton, FL.

Domsch, K.H.; Games, W. and Anderson, T. H. 1980. Compendium of soil fungi. Vol. 1. London, Academic Press, 859 pp.

Droby, S., Lichter, A. 2004. Post-harvest Botrytis infection: etiology, development and management. In: Elad, Y., Williamson, B., Tudzynski, P., Delen, N. (Eds.), Botrytis: Biology, Pathology and Control. Kluwer Academic Publishers, Dordrecht, The Netherlands, pp. 349-367.

Du, J., Gemma, H., Iwahori, S., 1997. Effects of chitosan coating on the storage of peach, Japanese pear and kiwifruit. J. Jpn. Hort. Sci. 66, 15-22.

El Ghaouth, A., Anil, J., and Ponnampalam, R. 1990. The effect of chitosan on growth and morphology of Rhizopus stolonifer. (Abstr.) Phytopathology 80:1020.

El Ghaouth, A., Arul, J., Grenier, J., Asselin, A., 1992. Antifungal activity of chitosan on two postharvest pathogens of strawberry fruits. Phytopathology 82, 398-402.

Elad Y (2000). Trichodema harzianum T39 preparation for biocontrol of plant diseases - control of Botrytis cinerea, Sclerotinia sclerotiorum and Cladosporium fulvum. Biocontrol Science and Technology 10: 499-507.

Fokkema, N.J. 1973. The role of saprophytic fungi in antagonism against Dreschslera sorokniama (Hellminthosporium sativum) on agar plates and on rye leaves with pollen. Physiol. Plant pathol., 3:195205.

Furuski, E., Ueno, Y., Sakairi, N., Nishi, N. and Tokura, S. 1996. Facile preparation and inculation ability of a Chitosan derivative bearing carbooxymethyl-bcyclodextrin. Carbohydr. Polym, Vol. 9, pp. 29-34.

Ge L.L., Zhang HY, Chen KP, Ma LC, Xu ZL. 2010. Effect of chitin on the antagonistic activity of Rhodotorula glutinis against Botrytis cinerea in strawberries and the possible mechanisms involved. Food Chem. 120:490-495.

Harman, G.E., Hayes, C.K, Lorito, M., Broadway, R.M., Di Pietro, A., Peterbauer, C. and Tronsmo, A. 1992. Chitinolytic Enzymes of Trichoderma harzianum: Purification of Chitobiosidase and Endochitinase. Melocular Plant Pathology. 83:313-318.

Hemeida, A.A. 1992. Rhizosphere mycoflora of potato and their role in seed and plant health in Egypt and Germany. Ph.D. Thesis, Fac. Agric. Alex. Univ., Egypt.

Hirano, S., and Nagao, N. 1989. Effect of chitosan, pectic acid, lysozyme and chitinase on the growth of several phytopathogens. Agric. Biol. Chem. 53:3065-3066.

Ibrahim, G.H. 1997. Studies on some wheat disease with reference to crown root-rot disease caused by Fusarium culmorum. Ph.D Thesis, Fac. Agric. Alex. Univ., Egypt.

Kendra, F. D., Christian, D., and Hadwiger, L. A. 1989. Chitosan oligomers from Fusarium solani/pea interactions, chitinase/ /3- glucanase digestion of sporelings and from fungal wall chitin actively inhibit fungal growth and enhance disease resistance. Physiol. Mol. Plant. Pathol. 35:215-230.

Kurita, K. 1986. Chemical modification of chitin and Cuitosan, p. 287-293. In R.A.A. Muzzarelli (ed.), Chitin in nature and technology. Plenum Press, New York. 
Leroux, P., Fritz, R., Debieu, D., Albertini, C., Lanen, C., Bach, J., Gredt, M. \& Chapeland, F. 2002. Mechanism of resistance to fungicides in field strains of Botrytis cinerea. Pest Management Science Vol.58, No.9, pp.876-888, ISSN 1526-4998.

Liu, X.F, Guan, Y.L., Yang, D.Z., Li, Z. and Yao, K.D. 2001. Antibacterial action of Chitosan and carboxymethylated Chitosan. J. Appl. Polym. Sci., Vol. 79, pp. 1324-1335.

Mass, J. L. 1998. Compendium of Strawberry Diseases, 3rd ed. American Phytopathological Society, St. Paul, MN.

Mauch, F., Hadwiger, L. A., and Boller, T. 1984. Ethylene: Symptom, not signal for the induction of chitinase and /3-1, 3-glucanase in pea pods by pathogens and elicitors. Plant Physiol. 76:607-611.

Neergaard, P. 1945. Danish species of Alternaria and Stemphylium, HamphryMillfor. Oxford University Press, London.566 pp.

Pearce, R. and Ride, J. P. 1982. Chitin and related compounds as elicitors of the lignification response in wounded wheat leaves. Physiol. Plant Pathol. 20:119-123.

Rabea, E.I.; El Badawy, M.T.; Stevens, C.V.; Smagghe, G.; Steurbaut, W. 2003. Chitosan as antimicrobial agent: Applications and mode of action Biomacromolecules, 4, 1457-1465.

Rifai, M.A. (1969). A revision off the genus Trichoderma common. Mycol. Inst., Mycol. Pap. 116.56pp.

Romanazzi G, Karabulut OA, Smilanick JL, 2007. Combination of chitosan and ethanol to control postharvest gray mold of table grapes. Postharvest Biology and Technology 45, 134-40.

Romanazzi G, Mlikota Gabler F, Smilanick JL, 2006. Preharvest chitosan and postharvest UV irradiation treatments suppress gray mold of table grapes. Plant Disease 90, 445-50.

Romanazzi G, Nigro E, Ippolito A, Di Venere D, Salerno M, 2002. Effects of pre- and postharvest chitosan treatments to control storage grey mold of table grapes. Journal of Food Science 67, 1862-7.

Şesan, T.E. (2003). Sustainable management of gray mould (Botrytis cinerea) on grapevine, strawberry and ornamentals. In: Chapter in advances in plant managenent, Huang, H.C., Surya A. (eds.). Res. Signpost Publ. House, 121-152.

Siti D. Y., Prima T. N., Riska A. and Erik M. 2009. The potential of chitosan as alternative biopesticide for postharvest plants. As. J. Food Ag-Ind. 2009, Special Issue, S241-S248.

Snedecor, G. W. and W. G. Cochran (1967). Statistical methods. The Iowa State University Press. 6th Edition. Ames, Iowa, USA.

Stossel, P., and Leuba, J. L. 1984. Effect of chitosan, chitin and some aminosugars on growth of various soilborne phytopathogenic fungi. Phytopathol. Z . 111:82-90.
Sugimoto, M., Morimoto, M., Sashiwa, H., Saimoto, H. and Shigemasa, Y. 1998. Preparation and characterization of water-soluble chitin and Chitosan derivatives. Carbohydr. Polym. Vol. 36, pp. 49-59.

Sutton, J. C. 1998. Botrytis Fruit Rot (Gray Mold) and Blossom Blight. Pp. 28-31 in: Compendium of Strawberry Diseases, 2nd edition, Maas, J. L. (ed.). APS Press. St. Paul, MN

Tolaimate, A.; Desbrie'res, J.; Rhazi, M.; Alagui, A.; Vincendon, M., and Vottero, P., 2000. On the influence of deacetylation process on the physicochemical characteristics of chitosan from squid chitin. Polymer, 41, 2463- 2469.

Townsend, G. K. and Heuberger, T. W. 1943. Methods for estimating losses caused by diseases in fungicides experiments. Plant Dis. Reptr., 27: 340 and 343.

Trotel-Aziz P, Couderchet M, Vernet G, Aziz A, 2006. Chitosan stimulates defense reactions in grapevine leaves and inhibits development of Botrytis cinerea. European Journal of Plant Pathology 114, 405-13.

Weber, R.W.S. 2011. Resistance of Botrytis cinerea to multiple fungicides in Northern German small fruit production. Plant Disease Vol.95, No.10, pp.12631269, ISSN 0191-2917.

Williamson, B., B. Tudzynski, P. Tudzynski, and J. A. L. van Kan. 2007. Botrytis cinerea: the cause of grey mould disease. Molecular Plant Pathology 8: 561580.

Wu, F., Guan, Z. and Whidden, A. 2012. Strawberry Industry Overview and Outlook, University of Florida.

Wu, T., Zivanovic, S., Draughon, F.A., Conway, W.S. and Sams C.E. 2005. Physiochemical properties and bioactivity of fungal chitin and Chitosan. Journal of Agriculture and Food Chemistry. 53, 3888-3894.

Xu, J. G., Zhao, X. M., Han, X. W., \& Du, T. G. 2007. Antifungal activity of oligochitosan against Phytophthora capsici and other plant pathogenic fungi in vitro. Pesticide Biochemistry and Physiology, 87, 220-228.

Yarahamdi, M., Saaei, Z. and Azizi, M. 2014. Study the effect of chitosan, vanillin, and acetic acid on fungal disease control of Rhizopus stolonifer in strawberry fruits in vitro and in vivo. European journal of Expermintal Biology 4(3): 219- 225.

Youn, D. K., No, H. K., \& Prinyawiwatkul, W. 2007. Physical characteristics of decolorized chitosan as affected by sun drying during chitosan preparation. Carbohydrate Polymers, 69, 707-712.

Yu T., Wang, LP., Yin, Y., Wang, YX., Zheng, XD. 2008. Effect of chitin on the antagonistic activity of Cryptococcus laurentii against Penicillium expansum in pear fruit. Int. J. Food Microbiol.122:44-48.

Zimand G., Elad Y and Chet Ilan. 1996. Effect of Trichoderma harzianum on Botrytis cineria Pathogenicty. The American Phytopathological Society. 86 (11): 1255-1260.

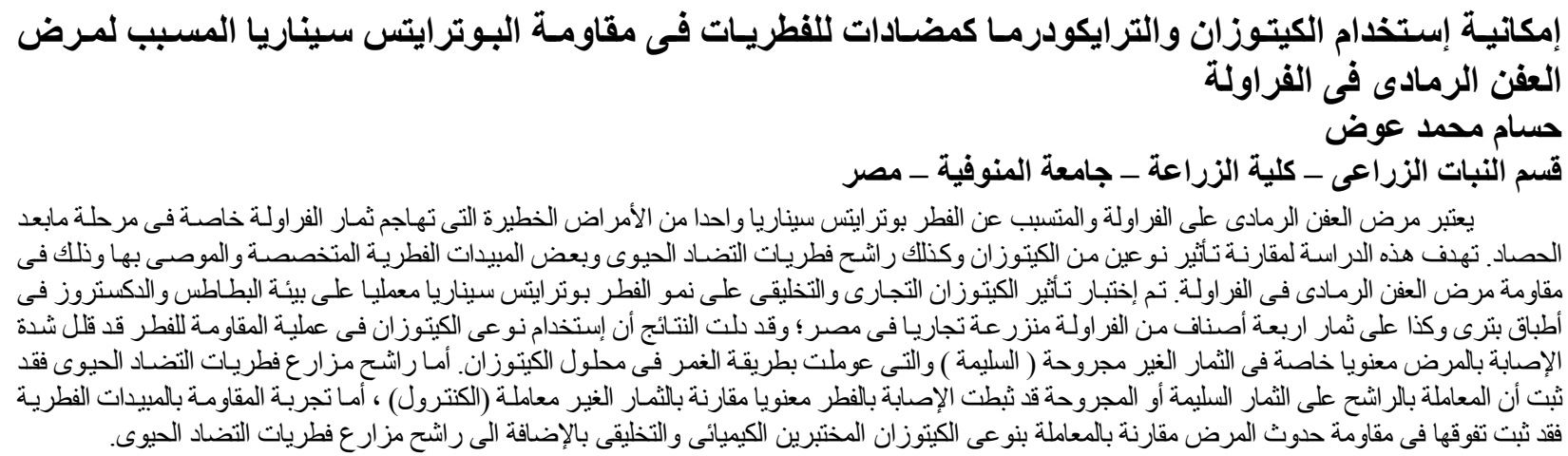

